\title{
Anatomical and histological changes in the oviducts of Japanese quail, Coturnix japonica, after embryonic exposure to ethynyloestradiol
}

\author{
C. Berg ${ }^{1}$, L. Holm², I. Brandt ${ }^{1}$ and B. Brunström ${ }^{1}$ \\ ${ }^{1}$ Department of Environmental Toxicology, Centre for Reproductive Biology in Uppsala, \\ Uppsala University, Norbyvägen 18 A, SE-752 36 Uppsala, Sweden; and \\ ${ }^{2}$ Department of Animal Physiology, Centre for Reproductive Biology in Uppsala, \\ Swedish University of Agricultural Sciences, Box 7045, SE-750 07 Uppsala, Sweden
}

Oestrogen is needed for normal oviductal development in female birds, but excessive early exposure to oestrogen can cause oviductal abnormalities and impair egg-laying ability. In this study, the anatomical and histological effects of in ovo exposure to the synthetic oestrogen ethynyloestradiol on the oviducts of immature and adult female Japanese quail, Coturnix japonica, were investigated. A series of abnormalities was observed after injection of ethynyloestradiol ( 2 or $20 \mathrm{ng} \mathrm{g}^{-1} \mathrm{egg}$ ) into the yolk on day 3 of incubation. Ethynyloestradiol induced precocious differentiation of the luminal epithelium and tubular glands in immature chicks. Right-side oviduct retention occurred at all the ages studied, whereas certain other effects were not evident until sexual maturity.
The left oviduct was reduced in size and tubular gland density in the uterus (shell gland) was reduced in sexually mature birds that had been treated with ethynyloestradiol. The utero-vaginal junction was longer than in control birds and had a higher tubular gland density. The epithelial cells in the magnum were taller in birds treated with ethynyloestradiol. Embryonic exposure to the environmental contaminant ethynyloestradiol may cause persisting structural malformations in oviducts of quails, which can impair fertility. As oviductal malformations are indicative of embryonic exposure to exogenous oestrogen, they are potentially useful as biomarkers of xenooestrogen exposure in wild bird populations.

\section{Introduction}

Oestrogens are a prerequisite for differentiation and development of the oviducts in female birds. Proliferation of the luminal epithelium and differentiation of ciliated and glandular cells are oestrogen-controlled processes (Kohler et al., 1969; Oka and Schimke, 1969; Palmiter and Wrenn, 1971; Sandoz et al., 1975). However, exposure of female embryos to oestrogen during early development can induce dose-dependent malformation of the Müllerian ducts (embryonic oviducts) (Berg et al., 1999). Berg et al. (1999) observed malformations at hatching, including a retained right-side Müllerian duct and small vesicles along the Müllerian ducts. Oestrogen treatment causes precocious differentiation of the epithelial cells in the Müllerian ducts into tubular gland cells in chicken embryos (Andrews and Teng, 1979; Teng and Teng, 1979). Oestrogen treatment in ovo causes abnormal oviducts in adult quail and domestic fowl (Greenwood and Blyth, 1938; Rissman et al., 1984; Gildersleeve et al., 1985); these abnormalities included

Email: cecilia.berg@etox.uu.se retention of the right-side oviduct and reduced size of the left oviduct. Other effects of oestrogen on the treated birds were inhibition of egg-laying abilities, production of eggs without shells and the presence of yolks outside the oviduct in the abdominal cavity (Greenwood and Blyth, 1938; Adkins, 1975; Rissman et al., 1984; Gildersleeve et al., 1985). It is not known what causes oestrogen-induced inhibition of egg-laying ability but it may be due to malformation of the oviducts (Rissman et al., 1984). To our knowledge, the histological effects of embryonic exposure to oestrogen on the subsequent adult avian oviducts have not been characterized previously.

The aim of the present study was to examine the anatomical and histological effects of exposure to oestrogen in ovo on the oviducts of juvenile and sexually mature quail. The synthetic oestrogen ethynyloestradiol, which is used commonly in contraceptive pills, was used as the test substance. Ethynyloestradiol was identified recently in effluents from municipal sewage treatment plants and ethynyloestradiol conjugates were detected in the bile of trout caged in such effluents. Consequently, ethynyloestradiol may be regarded as an environmental contaminant that is capable of feminizing male fish (Desbrow et al., 1998; Larsson et al., 1999). 


\section{Materials and Methods}

\section{Treatment of eggs and birds}

Japanese quail (Coturnix japonica) eggs were obtained from a local breeder (ESF-produkter; Estuna). The eggs were incubated at $37.5^{\circ} \mathrm{C}$ and $60 \%$ relative humidity and turned at $3 \mathrm{~h}$ intervals. $17 \alpha$-Ethynyloestradiol (ethynyloestradiol) (Sigma Chemical Co, St Louis, MO) was dissolved in a mixture of peanut oil and lecithin from which a water emulsion was prepared and used as vehicle (Brunström and Örberg, 1982; Brunström and Darnerud, 1983). On day 3 of incubation, $20 \mu \mathrm{l}$ emulsion ( 2 or $20 \mathrm{ng}$ ethynyloestradiol $\mathrm{g}^{-1}$ egg) was injected into the yolk of each egg through a small hole in the shell that had been punched with a needle at the blunt end of the egg. After injection, each shell was sealed with paraffin wax and the eggs were returned to the incubator. Control eggs were injected with vehicle only. On day 15 of incubation, the eggs were placed in hatching boxes at $37^{\circ} \mathrm{C}$ and $70 \%$ relative humidity until hatching occurred between day 17 and day 19. After hatching, the chicks were raised in mixed sex groups with turkey starter feed and tap water available ad libitum. The animal facility was lit for $16 \mathrm{~h}$ each day. The number of hatched eggs and mortality of chicks are shown (Table 1). The local ethics committee approved the study.

\section{Dissection and tissue preparation}

The birds were dissected at 1, 2, 4 or 8 weeks after hatching. In total, 50 birds were examined. The birds were killed by cervical dislocation. The oviducts were examined for gross abnormalities in situ. The chicks aged 1 or 2 weeks were examined under a dissecting microscope. The position of the egg in the oviduct was noted in the birds aged 8 weeks (Table 2).

Oviducts and residuals of oviducts were fixed in phosphate buffer $\left(0.1 \mathrm{~mol} \mathrm{I}^{-1}, \mathrm{pH} 7.0\right)$ containing $4 \%(\mathrm{w} / \mathrm{v})$ formaldehyde. The oviducts from sexually immature chicks (aged 1, 2 or 4 weeks) were divided into a cephalic (A) and a caudal (B) region (Fig. 1a) and embedded. All the birds aged 8 weeks had fully developed ovaries with large yolks and most of the control birds ( 5 of 7 ) and birds that received the lower dose of ethynyloestradiol ( $2 \mathrm{ng} \mathrm{g}^{-1}$ egg) (3 of 5) laid eggs. Therefore, these birds were considered to be sexually mature. Three transverse slices (about $2 \mathrm{~mm}$ thickness) were cut from each of the following regions from the oviducts of these birds: infundibulum; magnum (from cephalic, middle, and caudal regions); isthmus; uterus (shell gland; all three slices from middle region); and vagina. Slices from the utero-vaginal junction were cut length-wise (Fig. 1b). After dehydration in increasing concentrations of ethanol, the samples were embedded in hydroxyethyl methacrylate (Technovit; Leica Instruments $\mathrm{GmbH}$, Heidelberg). Duplicate sections $(3 \mu \mathrm{m}$ thickness) were cut with a microtome (Microm HM360; Carl Zeiss AB, Stockholm) using a glass knife. One of the duplicate sections was stained with haematoxylin and eosin using a laboratory microwave oven
Table 1. Number of quail chicks and chick mortality

\begin{tabular}{lccc}
\hline $\begin{array}{l}\text { Treatment } \\
\text { (ng ethynyloestradiol } \\
\mathrm{g}^{-1} \text { egg) }\end{array}$ & $\begin{array}{c}\text { Number of } \\
\text { chicks that } \\
\text { hatched }\end{array}$ & $\begin{array}{c}\text { Chick } \\
\text { mortality } \\
(\%)\end{array}$ & $\begin{array}{c}\text { Number } \\
\text { of females } \\
\text { examined }\end{array}$ \\
\hline 0 & 43 & $11.6(5)$ & 21 \\
2 & 40 & $12.5(5)$ & 15 \\
20 & 43 & $25.6(11)$ & 14 \\
\hline
\end{tabular}

(H2800 Microwave Processor, Energy Beam Sciences Inc., Agawam, MA), and the other was stained with toluidine blue. Toluidine blue stains mucus-secreting cells, such as the non-ciliated secretory cells in the luminal epithelium of the oviduct. Histological examination was performed using a light microscope and photomicrographs were taken with a Nikon Microphot-FXA imaging system.

\section{Morphometric analysis}

All measurements were made without prior knowledge of the treatment of the bird. The analyses were performed using a digital imaging system connected to a Leica DMRXE light microscope (Leica Microsystems Wetzlar $\mathrm{GmbH})$. In the chicks aged 1 week, the stage of epithelial differentiation was estimated by counting the number of ciliated cells in histological sections from region B. In adult quail, magnum epithelial height was determined by measuring the height of 15 epithelial cells in five different regions. The regions were selected to represent the tallest part of the epithelium in the tissue slice. One tissue slice per bird was analysed. The images were collected with a Hamamatsu Orca IIIm camera (Hamamatsu Photonics Norden) and the measurements were performed in Openlab v.2.2.0 (Improvision). The density of uterine glandular tissue was determined by measuring the glandular area in a uterine mucosal fold and relating it to the total area of the fold. Five folds were measured in each individual. The uterine measurements were made using Leica Q-win image processing and analysis software (Leica Microsystems Imaging Solution Ltd) and a Leica DC100 digital camera was used to collect the images.

\section{Statistical analysis}

Student's $t$ test was used for comparisons of body weight between control and ethynyloestradiol-treated birds. The Mann-Whitney $U$ test was used to compare birds treated with ethynyloestradiol and control birds in the histomorphometric analysis. The level of significance was $P<0.05$.

\section{Results}

\section{Gross morphology of the oviducts}

Immature birds (aged 1, 2 and 4 weeks). Each control chick $(n=14)$ had a left oviduct that extended from the cloaca to the anterior part of the abdominal cavity. The 
Table 2. Values from morphometric analysis of the oviducts from female quail aged 8 weeks after exposure to ethynyloestradiol in ovo

\begin{tabular}{|c|c|c|c|c|c|c|}
\hline \multirow{2}{*}{$\begin{array}{l}\text { Dose } \\
\text { (ng ethynyloestradiol } g^{-1} \\
\text { egg) }\end{array}$} & \multicolumn{2}{|c|}{ Oviductal length $(\mathrm{cm})$} & \multirow{2}{*}{$\begin{array}{c}\text { Uterine } \\
\text { glandular } \\
\text { density }(\%)^{\mathrm{a}}\end{array}$} & \multirow{2}{*}{$\begin{array}{c}\text { Length of } \\
\text { utero-vaginal } \\
\text { junction }(\mathrm{mm})^{b}\end{array}$} & \multirow{2}{*}{$\begin{array}{c}\text { Height of } \\
\text { magnal } \\
\text { epithelium }(\mu \mathrm{m})^{\mathrm{c}}\end{array}$} & \multirow{2}{*}{$\begin{array}{l}\text { Position of } \\
\text { egg in the } \\
\text { oviduct }\end{array}$} \\
\hline & Left & Right & & & & \\
\hline 0 & $>25$ & - & 96 & 2.6 & 20 & Shell gland \\
\hline 0 & $>25$ & - & 91 & 2.6 & 19 & No egg \\
\hline 0 & $>25$ & - & 95 & 2.2 & 25 & Shell gland \\
\hline 0 & $>25$ & - & 68 & 2.1 & 19 & Shell gland \\
\hline 0 & $>25$ & - & 78 & 2.1 & 17 & Shell gland \\
\hline 0 & $>25$ & - & 76 & 2.6 & 19 & Shell gland \\
\hline 0 & $>25$ & - & 96 & 2.3 & 27 & No egg \\
\hline 2 & 23 & 13.5 & 61 & 2.6 & 49 & No egg \\
\hline 2 & $>25$ & 8 & 68 & 4.7 & 26 & Shell gland \\
\hline 2 & 21 & 10 & 55 & nd & 24 & No egg \\
\hline 2 & 20 & 18 & 40 & 2.6 & 28 & Shell gland \\
\hline 2 & 22 & 9 & 85 & 3.4 & 38 & No egg \\
\hline 20 & 8.5 & 7 & 32 & 6.8 & 47 & No egg \\
\hline 20 & 16.5 & 13.5 & 66 & 6.0 & 36 & No egg \\
\hline 20 & 12.5 & 9.5 & 37 & 7.3 & 53 & No egg \\
\hline 20 & 8 & 2 & 68 & nd & 21 & No egg \\
\hline
\end{tabular}

Uterine glandular density: determined in histological sections through the uterus. The area occupied by tubular glands in a mucosal fold was determined and expressed as a percentage of total fold area. Five folds were measured in one section from each individual and the mean value is given.

Height of magnal epithelium: mean value for 75 selected cells (see Methods) from each bird.

aMean values for birds that received low $\left(2 \mathrm{ng} \mathrm{g}^{-1} \mathrm{egg} ; P<0.02\right)$ and high $\left(20 \mathrm{ng} \mathrm{g}^{-1}\right.$ egg; $\left.P<0.01\right)$ doses of ethynyloestradiol are significantly different from controls (Mann-Whitney $U$ test).

${ }^{b}$ Mean values for birds that received low $(P<0.05)$ and high $(P<0.02)$ doses of ethynyloestradiol are significantly different from controls $(M a n n-W h i t n e y ~ U$ test). ${ }^{c}$ Mean values for birds that received low $(P<0.02)$ and high $(P<0.05)$ doses of ethynyloestradiol are significantly different from controls $($ Mann-Whitney $U$ test). nd: not determined.

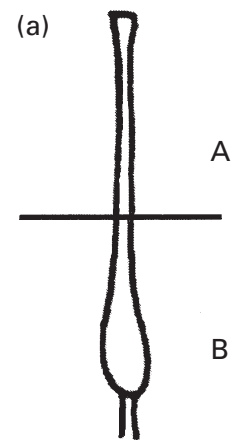

(b)

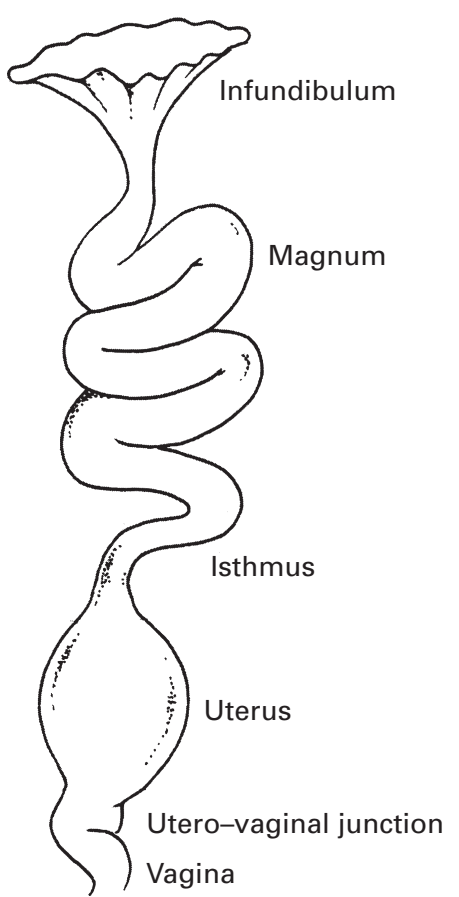

Fig. 1. (a) Schematic representation of an immature avian oviduct. A: proximal region. B: distal region. (b) Schematic representation of an oviduct of a sexually mature bird showing the distinct regions: infundibulum, magnum, isthmus, uterus (shell gland), utero-vaginal junction and vagina. oviduct wall was thin and almost translucent. The part of the duct forming the uterus at the caudal end of region $B$ was expanded (Fig. 1a). Two of the controls had a small vestigial duct on the right side. Along one of these ducts there were small vesicles filled with a clear fluid.

Embryonic exposure to ethynyloestradiol caused a retained right oviduct in all but two chicks (Table 3 ). In all the high dose females (those exposed to 20 ng ethynyloestradiol g ${ }^{-1}$ egg), the right oviduct was about half the length of the left oviduct, or longer. In the low dose (those exposed to $2 \mathrm{ng}$ ethynyloestradiol g ${ }^{-1}$ egg) females, the right duct was half the length of the left oviduct, or shorter. Vesicles along the oviduct were observed in all the chicks aged 1 or 2 weeks, six of eight high dose chicks and four of eight low dose chicks. The vesicles were usually located at the anterior end of the oviduct. Vesicle size varied from a few millimetres to $2 \mathrm{~cm}$ in diameter and the vesicles were filled with a clear fluid.

Sexually mature birds (aged 8 weeks). The control birds $(n=7)$ each had a left oviduct of normal size (Table 2), in which the different regions were clearly distinguishable. The wide, funnel-like infundibulum had very thin walls. The magnum had a thick wall and was separated from the isthmus by the distinct gland-free area. The uterus was a distended pouch-like structure, darker than the other parts of the oviduct. The short muscular most caudal part of the 
Table 3. Number of female quail with a retained right oviduct after exposure to ethynyloestradiol in ovo

\begin{tabular}{lccc}
\hline & \multicolumn{3}{c}{ Treatment } \\
\cline { 2 - 4 } Age (weeks) & Control & $\begin{array}{c}\text { 2 ng ethynyloestradiol g-1 egg } \\
\text { (low dose) }\end{array}$ & $\begin{array}{c}20 \text { ng ethynyloestradiol g-1 egg } \\
\text { (high dose) }\end{array}$ \\
\hline 1 & $1 / 5$ & $5 / 5$ & $5 / 5$ \\
2 & $1 / 3$ & $2 / 3$ & $3 / 3$ \\
4 & $0 / 6$ & $1 / 2$ & $2 / 2$ \\
8 & $0 / 7$ & $5 / 5$ & $4 / 4$ \\
\hline
\end{tabular}

oviduct formed the vagina. None of the control birds had a right oviduct. Yolk-like material was found in the abdominal cavity in one of the controls.

The body weight of the females that had been exposed to ethynyloestradiol was not significantly different from that of the control birds. However, several abnormalities in the oviducts were observed in the females that had been exposed to ethynyloestradiol: the length of the left oviduct was reduced (Table 2) and, in one female, the shell gland did not open into the vagina. A right oviduct was present in all the birds that had been exposed to ethynyloestradiol (Table 2). Yolk-like material was observed in the abdominal cavity of two birds that received the high dose of ethynyloestradiol and two birds that received the low dose.

\section{Histology}

Histological evaluation was based on the left oviduct, except for the treated birds aged 8 weeks, in which the right oviduct was also examined. Figures 2-10 are grouped to show ethynyloestradiol-treated birds compared with controls and are therefore not referred to in strict order in the text.

Immature birds (aged 1, 2 and 4 weeks). In control chicks aged 1 week the mucosa of region A was smooth, with few indentations, whereas region B had low rounded primary folds with shallow invaginations in the intervening grooves. The cells lining these invaginations were stained weakly compared with other cells in the epithelium (Fig. 2).

In control chicks aged 2 weeks, primary folds occurred in region $\mathrm{A}$ too. The folds of region $\mathrm{B}$ were more differentiated than in the chicks aged 1 week, as they contained a few small intervening glands. The glandular cells were low columnar non-ciliated and stained weakly.

In the control chicks aged 4 weeks, region A contained numerous primary folds and shallow invaginations, with a few small glands. One bird had glands containing bright pink granules. In region $\mathrm{B}$, the mucosa had thickened considerably and the primary folds were finger-like, with numerous small secondary folds. Glands were observed in the mucosa at the base of the secondary folds (Fig. 5a) and throughout the entire fold in one bird.

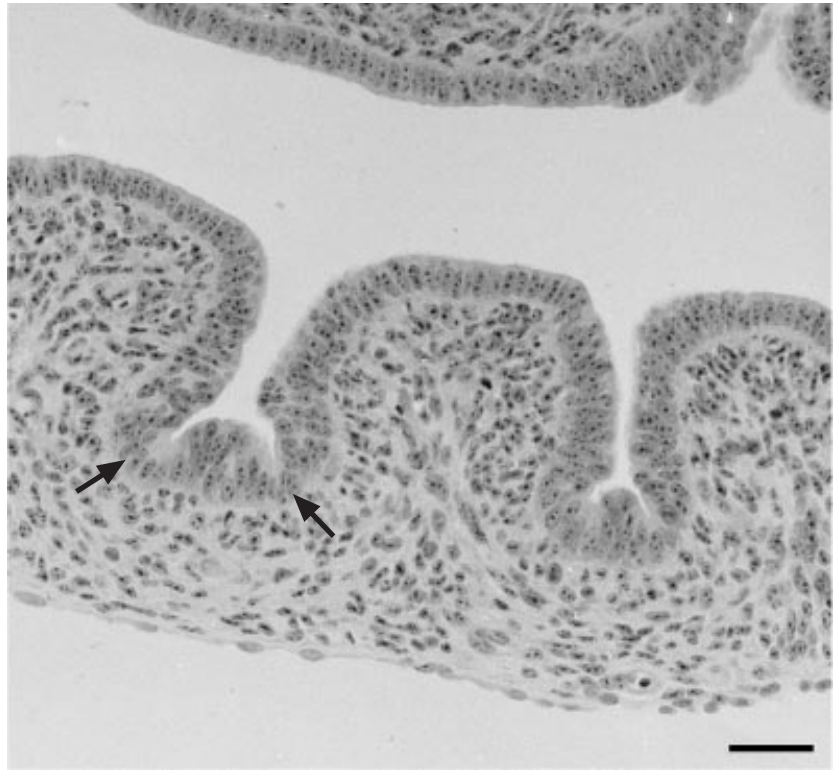

Fig. 2. Region B of an oviduct from a control chick aged 1 week in which low rounded folds with shallow invaginations are visible (arrows). Luminal epithelium is columnar and non-ciliated. Haematoxylin-eosin staining. Scale bar represents $30 \mu \mathrm{m}$.

The luminal epithelium of the entire oviduct was of a low columnar type and in the chicks aged 1 week it consisted of non-ciliated cells only. In chicks aged 2 weeks, the columnar epithelium was taller and occasional ciliated cells were found. In the chicks aged 4 weeks, more cells were ciliated (Fig. 5b). Strands of smooth muscle were already present in region $B$ in the chicks aged 1 or 2 weeks. In chicks aged 4 weeks, a smooth muscle layer had developed in this region, whereas only strands of muscle were observed in region $\mathrm{A}$.

In region $A$ from high dose chicks aged 1 week, the mucosa had numerous primary folds with shallow invaginations. In region B the primary folds were taller and the presence of secondary folds made them appear leaf-like. Small glands were observed at the base of the folds in both regions. The glandular cells were cuboid, non-ciliated and stained less intensely than the other epithelial cells (Fig. $4 a)$. In the low dose chicks aged 1 week, the folds were 


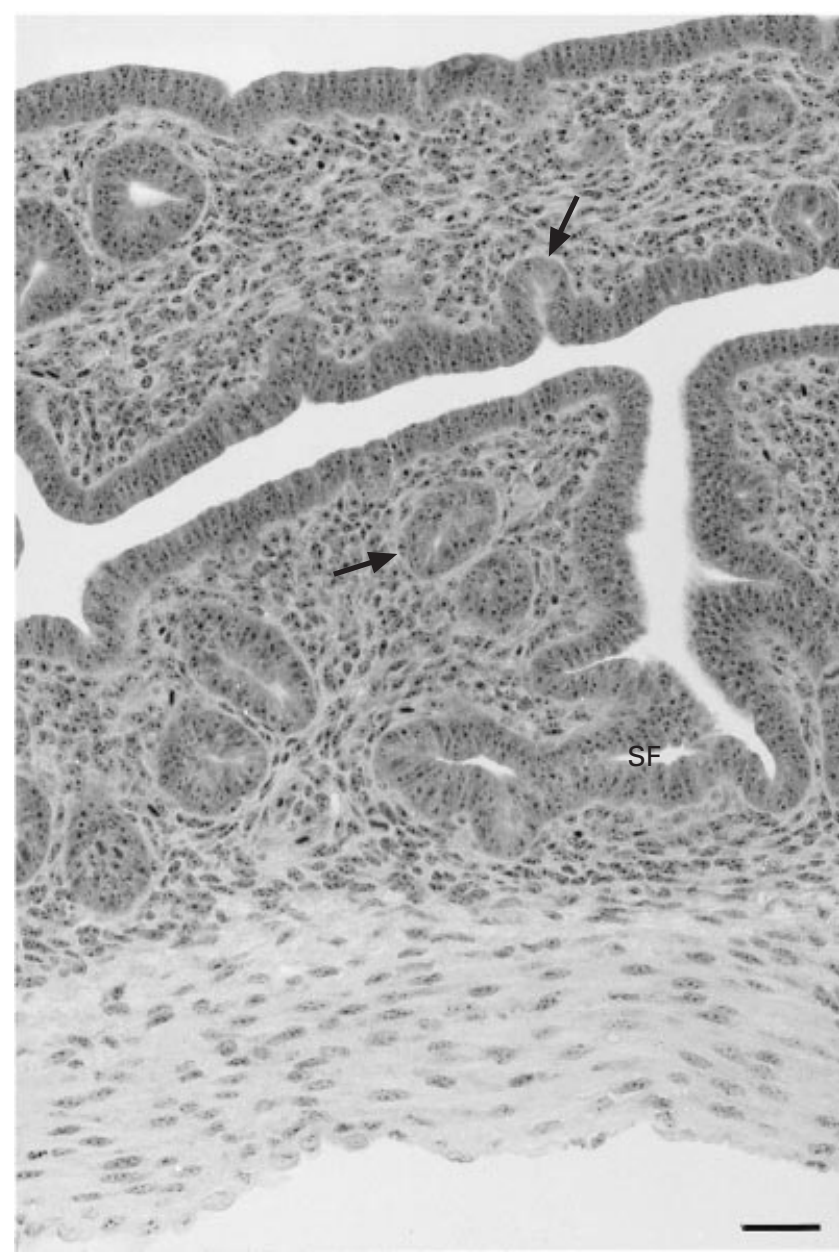

Fig. 3. Region $B$ of an oviduct from a chick aged 1 week that received 2 ng ethynyloestradiol $\mathrm{g}^{-1}$ egg. Primary folds and one secondary fold are visible (SF). Small glands are evident in the mucosa (arrows). Luminal epithelium is columnar and nonciliated. Haematoxylin-eosin staining. Scale bar represents $30 \mu \mathrm{m}$.

not as tall as in the high dose chicks. Weakly stained nonciliated cells lined the shallow invaginations in both regions and a few small glands were observed in region $B$ (Fig. 3).

In chicks aged 2 weeks, glands were present in both regions of high dose chicks. In the low dose chicks, small glands were observed in region B only. The primary folds were taller in the chicks aged 2 weeks than in the low dose chicks aged 1 week and contained some secondary folds. In chicks aged 4 weeks, the mucosal folds had increased in size, especially in the high dose chicks. Region B had numerous secondary folds and invaginations with tubular glands in the connective tissue (Fig. 6a). Region A had lower folds with fewer glands. In the low dose chicks, the primary folds were lower than in the high dose chicks and about as developed as in the high dose chicks aged 2 weeks. The folds were taller in region B than in region $\mathrm{A}$.
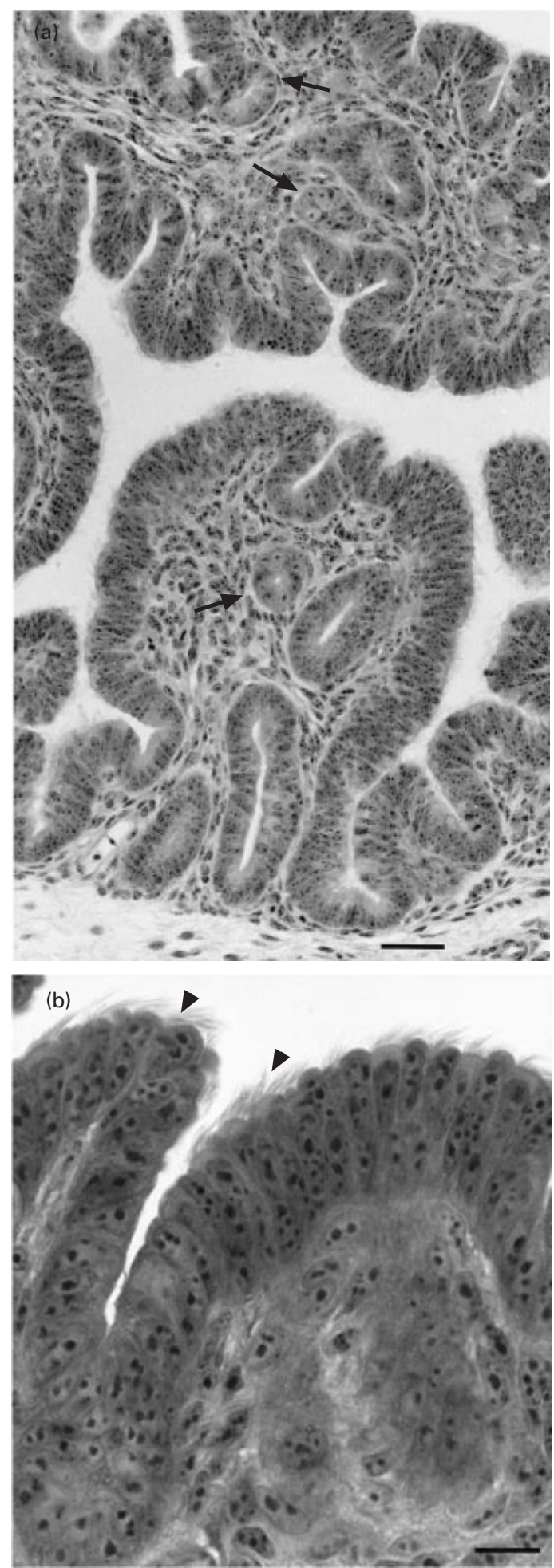

Fig. 4. Region B of an oviduct from a chick aged 1 week that received 20 ng ethynyloestradiol $g^{-1}$ egg. (a) Well-developed primary folds with secondary folding and several glands (arrows) are visible. Luminal epithelium is columnar, containing both nonciliated and ciliated cells. Haematoxylin-eosin staining. Scale bar represents $30 \mu \mathrm{m}$. (b) Luminal epithelium at a higher magnification with columnar ciliated cells (arrowheads). Haematoxylineosin staining. Scale bar represents $10 \mu \mathrm{m}$. 

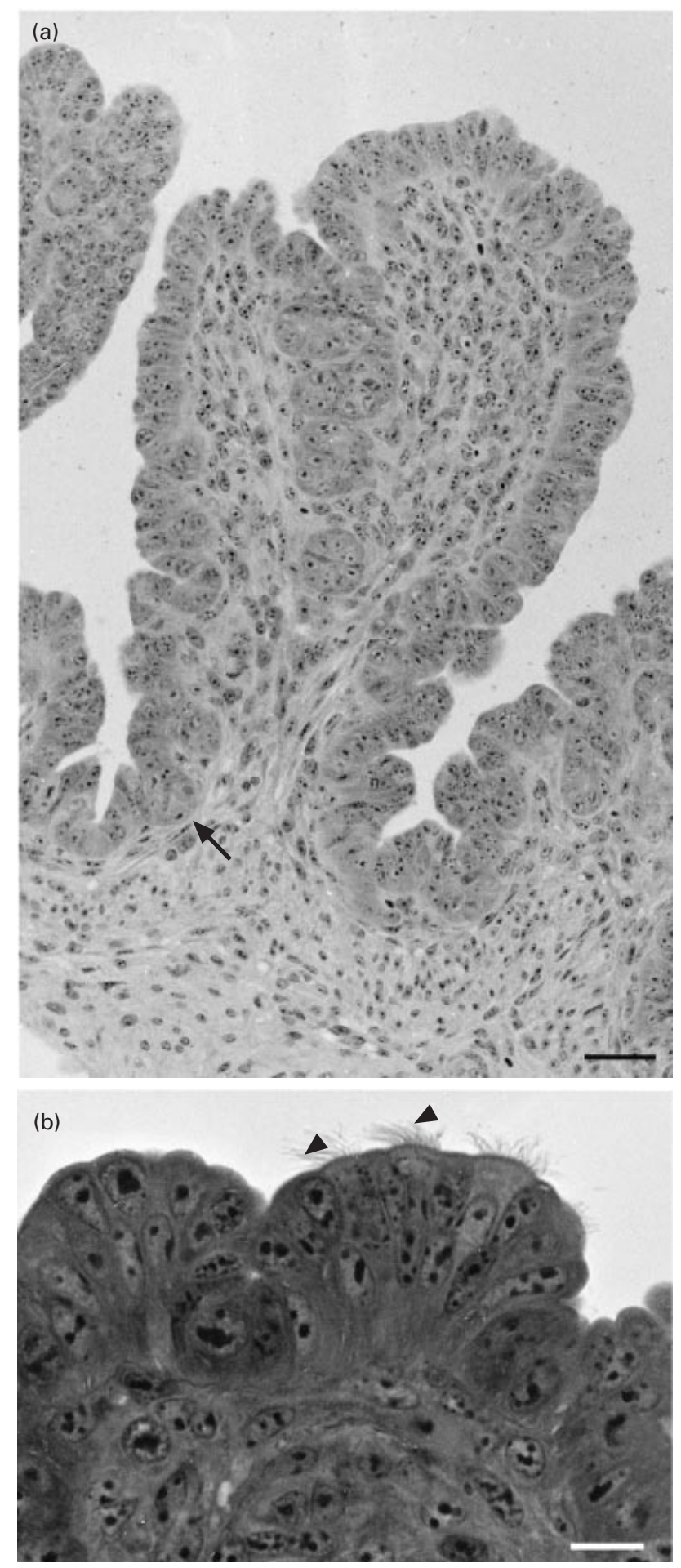

Fig. 5. Region B of an oviduct from a control chick aged 4 weeks. (a) A primary fold with shallow invaginations where small glands have started to form (arrow) is visible. Luminal epithelium is mainly columnar and non-ciliated. Haematoxylin-eosin staining. Scale bar represents $30 \mu \mathrm{m}$. (b) Luminal epithelium with a few ciliated cells (arrowheads). Haematoxylin-eosin staining. Scale bar represents $10 \mu \mathrm{m}$.
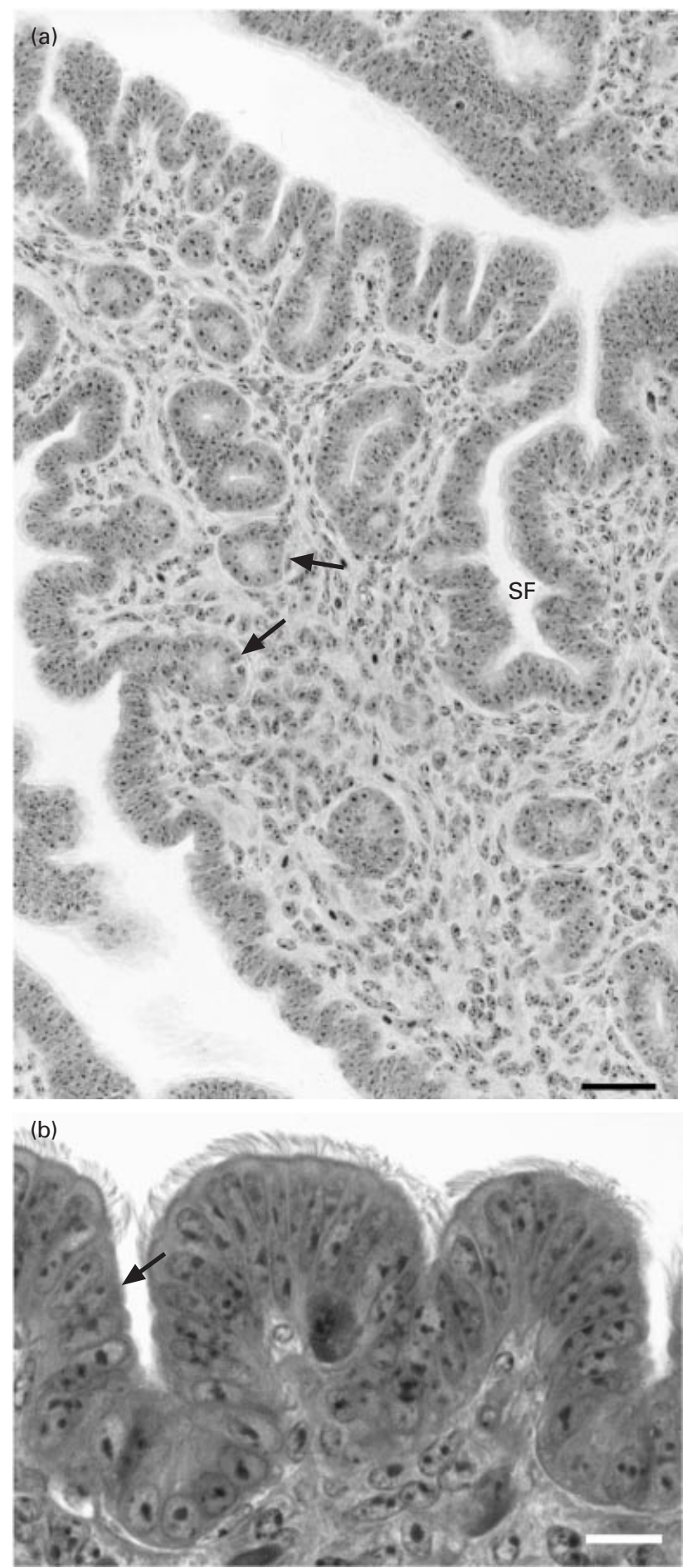

Fig. 6. Region B of an oviduct from a chick aged 4 weeks that received 20 ng ethynyloestradiol g ${ }^{-1}$ egg. (a) Primary folds are well developed and secondary folds are visible (SF). Numerous glands are visible in the mucosa (arrows). Haematoxylin-eosin staining. Scale bar represents $30 \mu \mathrm{m}$. (b) Ciliated cells of luminal epithelium are clearly distinguishable from the non-ciliated cells lining the gland (arrow). Haematoxylin-eosin staining. Scale bar represents $10 \mu \mathrm{m}$. 
The luminal epithelium differentiated earlier in the ethynyloestradiol-treated birds than in the control birds. Ciliated cells were observed in all the ethynyloestradioltreated chicks aged 1 week, (Fig. 4b) but not in control chicks at this age. All the high dose chicks $(n=5)$ had $>100$ ciliated cells in a section through region $\mathrm{B}$. The low dose chicks had between 2 and 51 ciliated cells in such a section. In chicks aged 2 weeks, ciliated cells were abundant in high dose chicks and occurred sparsely in low dose chicks. In chicks aged 4 weeks, the epithelium was mostly ciliated in both low and high dose chicks (Fig. 6b). In one high dose chick, secretory cells were also present in the epithelium.

Furthermore, region A of the oviducts from two of the high dose chicks aged 2 weeks had vesicles lined with both ciliated and non-ciliated cuboidal cells, surrounded by a thin layer of connective tissue with a few smooth muscle cells.

Smooth musculature was present as a thin layer in region $\mathrm{A}$ and as a thicker layer in region $\mathrm{B}$, in chicks aged 1 week. In chicks aged 2 weeks, the muscle layer was slightly thicker and in chicks aged 4 weeks it was even thicker. It was generally thicker in the oviducts of high dose chicks than of low dose chicks.

Left oviduct from mature birds (aged 8 weeks old). The infundibulum of control birds was thin and highly folded, especially the funnel. The luminal epithelium consisted mainly of columnar ciliated cells. Towards the magnum, low longitudinal ridges appeared and cuboidal non-ciliated cells were observed in the grooves between the ridges.

One high dose and one low dose bird had yolk-like material embedded in the infundibular mucosa (Fig. 7a), which was surrounded by a normal infundibular epithelium and glands and epithelium similar to those observed in the magnum (Fig. 7b).

The luminal epithelium of the magnum of control birds was simple, columnar and consisted of alternating ciliated cells and non-ciliated secretory cells. The secretory material in the non-ciliated cells was stained violet or pink by toluidine blue (Fig. 8a). The mucosal folds of the magnum were packed with glands that were filled with intensely stained granules.

In the high dose birds, the epithelial height was significantly increased compared with the control birds (Table 2 ). The non-ciliated cells were more numerous than the ciliated cells. Furthermore, the non-ciliated cells were distended greatly by secretory material and the basally located nuclei appeared condensed (Fig. 8c). These effects were less pronounced in the low dose birds but the epithelial height was significantly increased compared with the control birds (Fig. 8b). The mucosal folds largely resembled those of the control oviduct.

In the control birds, the isthmus contained glands that largely resembled those in the magnum, except that there were fewer and less densely packed granules. The epithelium consisted of alternating ciliated and non-ciliated cells,
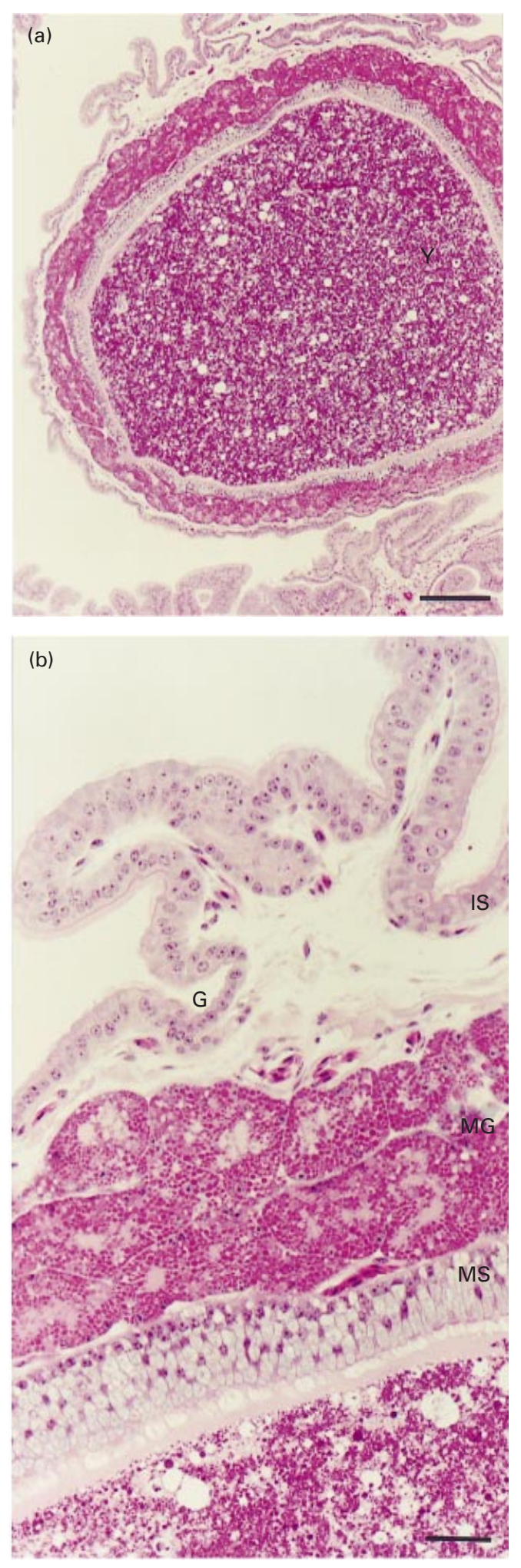

Fig. 7. Infundibulum from a sexually mature high-dose bird. (a) Yolk-like material $(\mathrm{Y})$ embedded in the mucosa. Haematoxylineosin staining. Scale bar represents $200 \mu \mathrm{m}$. (b) Infundibular surface epithelium (IS) with a glandular groove (G) is visible, as are glands (MG) and surface epithelium (MS) typical of the magnum. Haematoxylin-eosin staining. Scale bar represents $30 \mu \mathrm{m}$. 


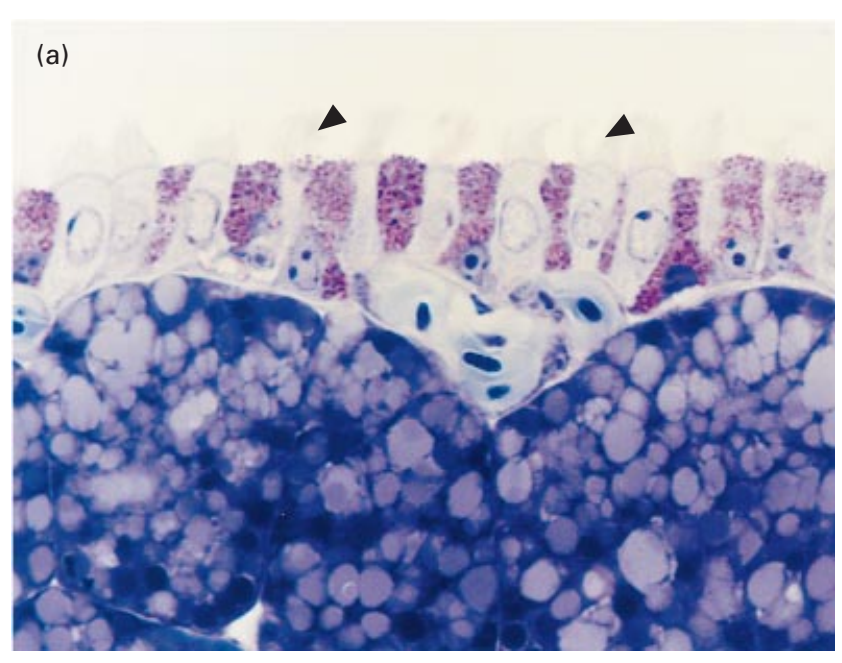

(b)

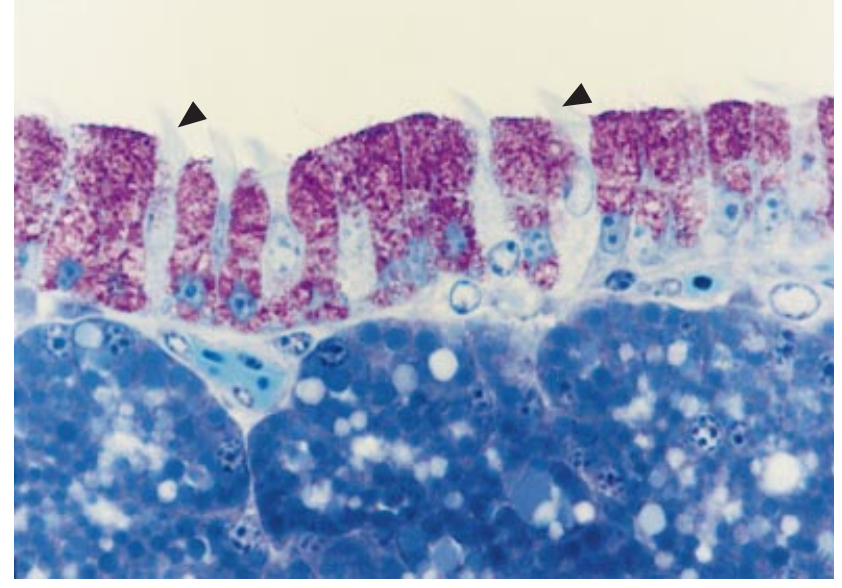

(c)

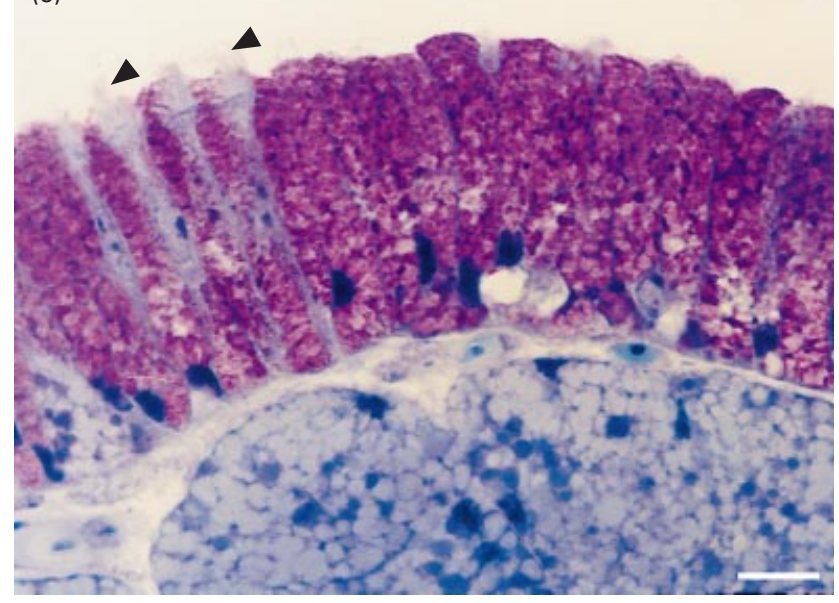

Fig. 8. Epithelium of magnum from sexually mature birds. (a) Control bird with alternating ciliated cells (arrowheads) and nonciliated secretory cells containing granular material. (b) Bird that received 2 ng ethynyloestradiol $g^{-1}$ egg that has taller cells than control birds and more non-ciliated than ciliated cells (arrowheads). (c) High-dose bird with cells nearly twice as tall as those in control birds and only a few narrow ciliated cells (arrowheads). Toluidine blue staining. Scale bar represents $10 \mu \mathrm{m}$. as in the magnum, but the mucosal folds contained more secondary folds. No effect of ethynyloestradiol treatment was found in the isthmus of the left oviduct.

The uterine glands of the control birds were distributed evenly in the leaf-like mucosal folds and were interspersed with blood capillaries (Fig. 9a). The glandular cells were cuboidal and the lumen was invariably narrow (Fig. 9b). The epithelium consisted of both ciliated and non-ciliated cells.

In the ethynyloestradiol-treated birds, the uterine morphology was disrupted, and a mixture of typical uterine glands and larger glands was observed. The larger glands had a wider lumen and either resembled sperm storage tubules (see descriptions of utero-vaginal junctions below) or were intermediate between normal glands and sperm storage tubules. Furthermore, the density of uterine glands was reduced (Table 2), especially in the apical half of the primary folds (Fig. 10a, b). The epithelium consisted of alternating ciliated and non-ciliated cells.

Longitudinal sections through the utero-vaginal junctions of control birds contained $24 \pm 5$ tubular glands, the so-called sperm storage tubules (Fujii and Tamura, 1963). The tubular glands are larger than uterine glands and usually have a wider lumen (insert Fig. 9b). The vaginal epithelium consisted mainly of columnar ciliated cells and appeared to be pseudostratified.

The utero-vaginal junction was significantly longer in the ethynyloestradiol-treated birds than in the control birds (Table 2). The number of glands resembling sperm storage tubules in longitudinal sections was $>100$ in all the high dose birds and $40 \pm 12$ in the low dose birds. No effect of ethynyloestradiol on the vaginal epithelium was observed.

Right oviduct from mature ethynyloestradiol-treated birds (aged 8 weeks). Yolk-like material embedded in the infundibular mucosa was observed in the right oviduct from one high dose bird. The mucosal folds in magnum of the right oviducts largely resembled those of the left control oviduct, except in one high dose bird, which had fewer glands containing fewer granules. The isthmus resembled that in the left control oviduct except in two high dose birds. One of these birds had a shorter isthmus and the other lacked an isthmus. The uterine glandular tissue of one low dose bird and three high dose birds resembled that of the left oviducts from the high dose birds.

\section{Discussion}

The results of the present study indicate that exposure of female quail embryos to oestrogen induces a series of structural changes in the left oviduct and retention of the right oviduct. Certain ethynyloestradiol-induced gross anomalies, such as vesicles on the oviducts, occurred in the chicks aged 1 and 2 weeks, but were not observed in the 

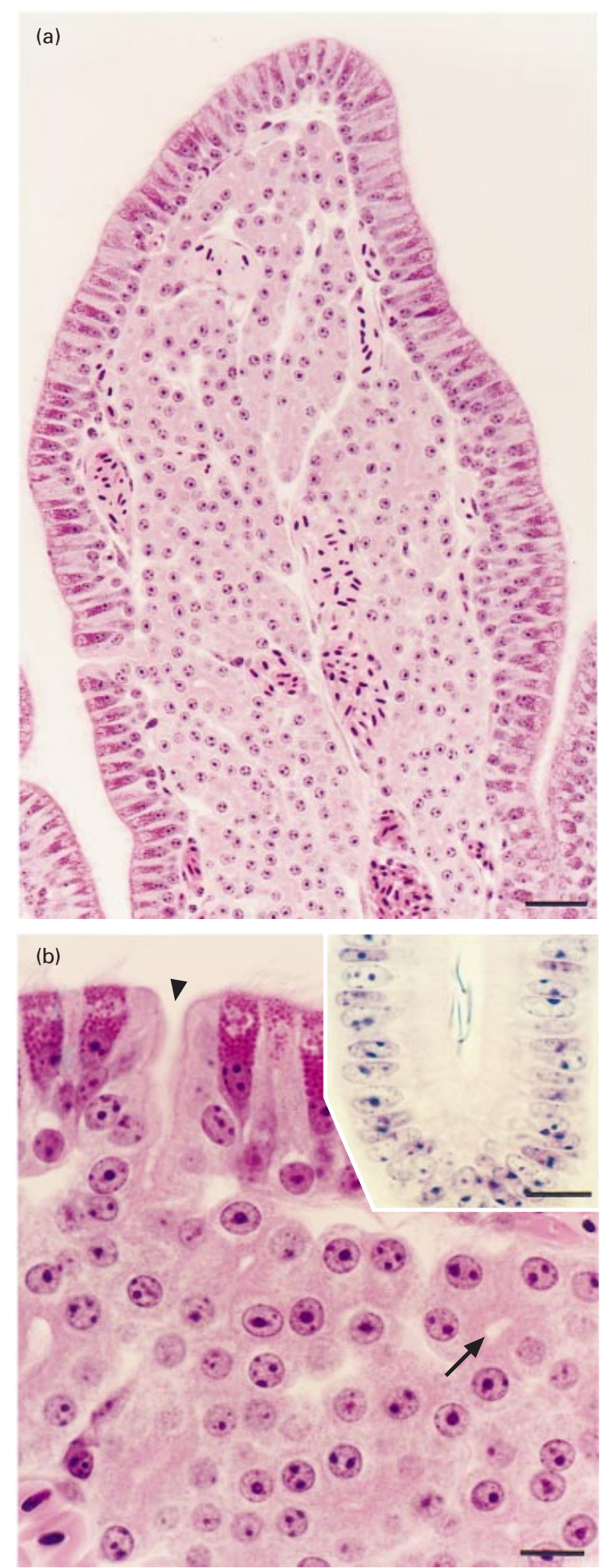

Fig. 9. Mucosal fold of uterus from a sexually mature control bird. (a) A dense mass of glands interspersed with capillaries is visible. The epithelium is simple columnar with alternating ciliated and non-ciliated cells. Haematoxylin-eosin staining. Scale bar represents $30 \mu \mathrm{m}$. (b) Uterine glands. Arrow: narrow lumen of uterine birds aged 4 and 8 weeks. Other effects did not become evident until sexual maturation, such as reduced size of the left oviduct. Reduction in the size of the left oviduct and presence of a right duct have been observed previously in adult quail after embryonic exposure to diethylstilboestrol and oestradiol benzoate, at doses at least 100 times higher than the dose used in the present study (Rissman et al., 1984; Gildersleeve et al., 1985). Consequently, the results of the present study show that embryonic exposure to the environmental pollutant ethynyloestradiol disrupts the adult oviduct at far lower doses than previously reported for other oestrogens.

The detailed histological investigation showed that in ovo exposure to oestrogen causes a number of histological abnormalities in various parts of adult quail oviducts. The disorganized glandular tissue observed in both the infundibulum and uterus could be a consequence of the observed precocious differentiation of the luminal epithelium into glandular and ciliated cells. As early as 1 week after hatching, both tubular glands and ciliated cells had developed in the oviducts of chicks that received 20 ng ethynyloestradiol g-1 egg (high dose chicks), but were only present sparsely in the control chicks aged 4 weeks. This finding is consistent with an earlier report that, in quail, differentiation of the epithelium begins between week 3 and week 4 of age (Pageaux et al., 1984). Precocious differentiation of the luminal epithelium in the Müllerian ducts has been observed in chicken embryos treated with diethylstilboestrol (Andrews and Teng, 1979; Teng and Teng, 1979).

The infundibulum actively engulfs the ovum after ovulation and is also the site of fertilization. Therefore, correct functioning of this region is crucial for egg production. In the present study, yolk-like material was embedded in the infundibular mucosa of the left oviduct in two of the birds that had been exposed to ethynyloestradiol, indicating disturbed functioning in this region. The effects of ethynyloestradiol on fertility were not investigated in the present study. However, egg-laying ability was impaired in adult quail after exposure to 7 ng ethynyloestradiol $\mathrm{g}^{-1}$ egg in ovo (K. Halldin, unpublished).

Increases in the relative number of non-ciliated secretory cells and overall epithelial height were observed in the luminal epithelium of the magnum of birds that had been exposed to ethynyloestradiol. Normally, the secretory cells release some of their granules as the yolk passes through the magnum, thus reducing the height of the epithelial cells (Sandoz et al., 1971). Thus, the increased epithelial height could be a consequence of no eggs having passed through the magnum. However, it is unlikely that this possibility explains the prominent changes observed in the epithelium fully, as three of four high dose birds had a

gland. Arrowhead: gland opening in the luminal epithelium. Haematoxylin-eosin staining. Scale bar represents $10 \mu \mathrm{m}$. Inset shows a sperm storage tubule (containing spermatozoa) in the utero-vaginal junction with a wider lumen than the uterine glands. Scale bar represents $10 \mu \mathrm{m}$. 


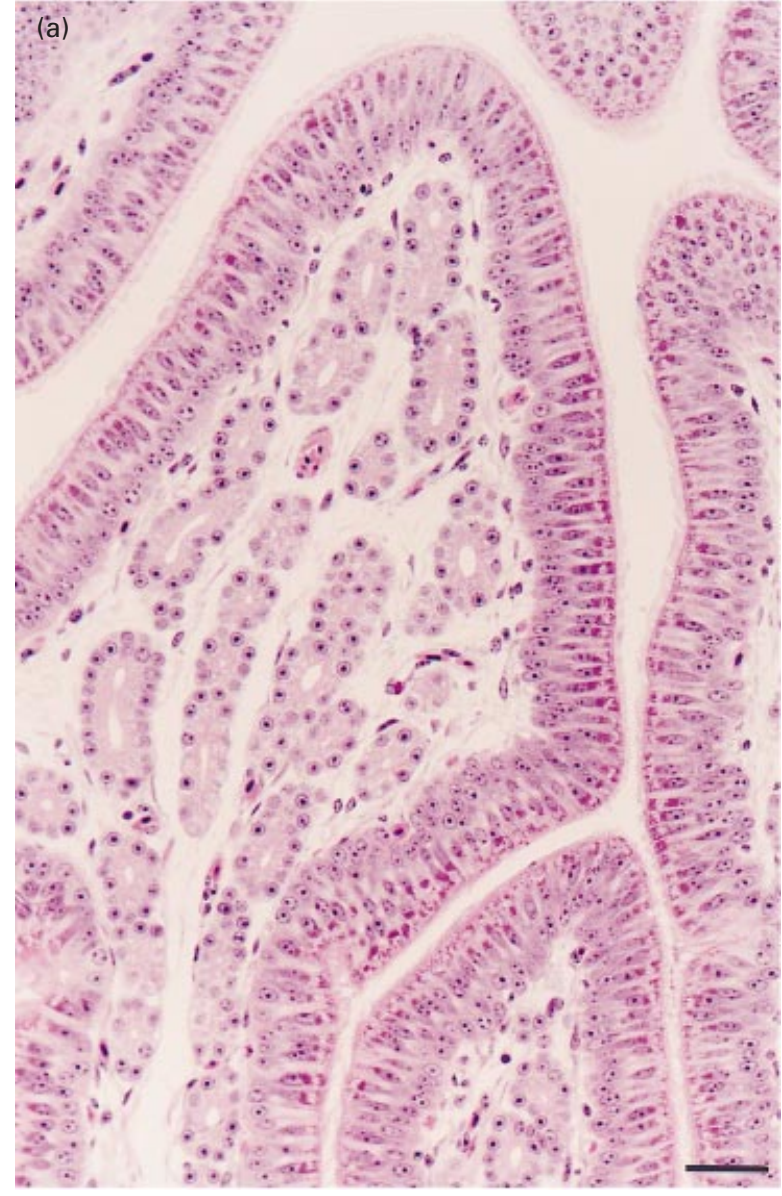

(b)

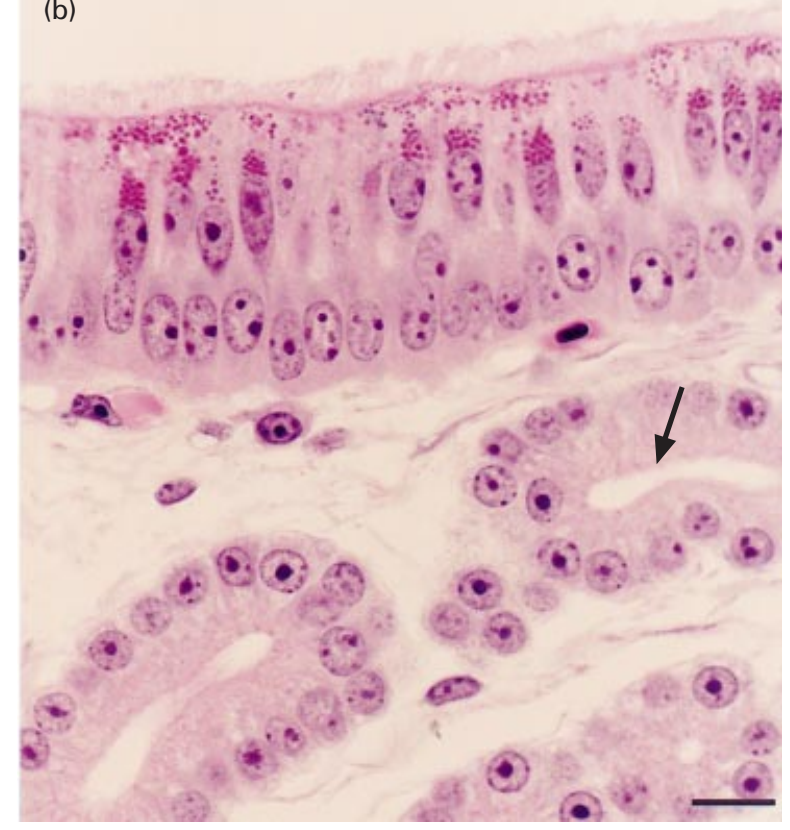

Fig. 10. Mucosal fold of uterus from a sexually mature bird that received 20 ng ethynyloestradiol g-1 egg. (a) Glands are fewer and slightly larger than in control birds and some have a clearly visible lumen. The luminal epithelium is simple columnar with substantially higher epithelium than did the two control birds that lacked an egg in the oviduct.

The pronounced structural changes in the uterus observed in the present study may impair shell formation. Uterine malformation could explain early observations that domestic hens produce eggs without shells after embryonic oestrogen treatment (Greenwood and Blyth, 1938). These authors also observed macroscopic deformities and shortening of the vagina. Although gross malformation of the vagina was not observed in the present study, the uterovaginal junctions were longer and contained more sperm storage tubules than those of the controls. The structural changes in the adult uterus and utero-vaginal junction could result from precocious differentiation of oviductal tubular glands in the immature oviduct. The effects of these malformations on fertility remain to be elucidated.

Certain environmental pollutants can interfere with hormone systems by mimicking or counteracting the action of natural hormones. Several of these endocrine disrupters have been shown experimentally to cause abnormalities in the reproductive organs of mammals, birds, reptiles and fish (Gellert, 1978; Fry and Toone, 1981; Bergeron et al., 1994; Guillette et al., 1994; Gimeno et al., 1996). There is also evidence that endocrine disruption occurs in vertebrate populations living in the wild (for review see Tyler et al., 1998; Vos et al., 2000). Right oviduct retention has been observed in embryos and chicks of herring gulls and glaucous-winged gulls in the USA, possibly resulting from exposure to oestrogenic environmental pollutants (Fry et al., 1987; Fox, 1992).

A number of bioassays have been developed to test chemicals that mimic the action of oestrogen (for review see Ankley et al., 1998). In birds, malformation of the Müllerian ducts in quail embryos has been suggested as a test endpoint for oestrogenic activity (Berg et al., 1998; 1999). In the present study, embryonic exposure to oestrogen induced changes in the oviduct that were not evident until sexual maturity. One explanation might be that premature oestrogen stimulation causes a change in the sensitivity of immature oviducts to hormonal stimuli during sexual maturation, resulting in disrupted differentiation. It is well known that organizational effects may not become apparent until endogenous hormone concentrations increase during sexual maturation (for reviews see Bern, 1992 and Guillette et al., 1995). Accordingly, the results of the present study highlight the importance of exposure during critical organizational periods when testing chemicals that disrupt the endocrine system. Furthermore, the finding that changes in the Müllerian ducts induced by oestrogen during embryonic development can be observed in the oviducts of both immature and adult birds supports the use of Müllerian duct

alternating ciliated and non-ciliated cells. Haematoxylin-eosin staining. Scale bar represents $30 \mu \mathrm{m}$. (b) Enlarged uterine glands with wider lumen (arrow) than in control birds. Haematoxylineosin staining. Scale bar represents $10 \mu \mathrm{m}$. 
and oviduct malformation as biomarkers for embryonic exposure of wild bird populations to oestrogenic pollutants.

In conclusion, exposure of quail to the environmental oestrogen ethynyloestradiol in ovo resulted in long-lasting structural malformations in the oviducts, including a series of histological changes. Right oviduct retention occurred at all ages studied, whereas some abnormalities of the left oviduct were evident in the sexually mature birds only. Thus, minor anatomical changes in the immature oviduct portend histological abnormalities in the adult oviduct, which may imply functional impairment. The usefulness of structural oviductal abnormalities as biomarkers for oestrogenic effects in wild birds should be considered.

Y. Ridderstråle is acknowledged for her valuable comments on the manuscript. The authors are grateful to M. Mattsson and I. Wennerberg for their expert technical assistance. S. Gunnarsson is acknowledged for his advice about histomorphometric analysis. This study was supported by the Foundation for Strategic Environmental Research (MISTRA) and the Swedish Council for Forestry and Agricultural Research (SJFR).

\section{References}

Adkins EK (1975) Hormonal basis of sexual differentiation in the Japanese quail Journal of Comparative Physiology and Psychology 89 61-71

Andrews GK and Teng CS (1979) Prenatal effect of oestrogenic hormone on tubular-gland cell morphogenesis and ovalbumin gene expression in the chick mullerian duct Biochemical Journal 182 271-286

Ankley G, Mihaich E, Stahl R et al. (1998) Overview of a workshop on screening methods for detecting potential (anti-)estrogenic/androgenic chemicals in wildlife Environmental Toxicology and Chemistry 17 68-87

Berg C, Halldin K, Brunström B and Brandt I (1998) Methods for studying xenoestrogenic effects in birds Toxicology Letters 102-103 671-676

Berg C, Halldin K, Fridolfsson A-K, Brandt I and Brunström B (1999) The avian egg as a test system for endocrine disrupters: effects of diethylstilbestrol and ethynylestradiol on sex organ development Science of the Total Environment 233 57-66

Bergeron JM, Crews D and McLachlan JA (1994) PCBs as environmental estrogens: turtle sex determination as a biomarker of environmental contamination Environmental Health Perspectives 102 780-781

Bern HA (1992) The fragile fetus. In Chemically Induced Alterations in Sexual and Functional Development: The Wildlife/Human Connection pp 9-15 Eds T Colborn and C Clement. Princeton Scientific Publishing, Princeton

Brunström B and Darnerud PO (1983) Toxicity and distribution in chick embryos of $3,3^{\prime}, 4,4^{\prime}$-tetrachlorobiphenyl injected into the eggs Toxicology 27 103-110

Brunström B and Örberg J (1982) A method for studying embryotoxicity of lipophilic substances experimentally introduced into hens' eggs Ambio 11 209-211

Desbrow C, Routledge EJ, Brighty GC, Sumpter JP and Waldock M (1998) Identification of estrogenic chemicals in STW effluent. 1. Chemical fractionation and in vitro biological screening Environmental Science and Technology 32 1549-1558

Fox GA (1992) Epidemiological and pathological evidence of contaminantinduced alterations in sexual development in free-living wildlife. In Chemically Induced Alterations in Sexual and Functional Development: The Wildlife/Human Connection pp 147-158 Eds T Colborn and C Clement. Princeton Scientific Publishing, Princeton

Fry DM and Toone CK (1981) DDT-induced feminization of gull embryos Science 213 922-924
Fry DM, Toone CK, Speich SM and Peard RJ (1987) Sex ratio skew and breeding patterns of gulls: demographic and toxicological considerations Studies in Avian Biology 10 26-43

Fujii S and Tamura T (1963) Location of sperms in the oviduct of the domestic fowl with special reference to storage of sperms in the vaginal gland Journal of Faculty of Fisheries and Animal Husbandry (Hiroshima University) 5 145-163

Gellert RJ (1978) Uterotrophic activity of polychlorinated biphenyls (PCB) and induction of precocious reproductive aging in neonatally treated female rats Environmental Research 16 123-130

Gildersleeve RP, Tilson HA and Mitchell CL (1985) Injection of diethylstilbestrol on the first day of incubation affects morphology of sex glands and reproductive behaviour of Japanese quail Teratology 31 101-109

Gimeno S, Gerritsen A, Bowmer T and Komen H (1996) Feminization of male carp Nature 384 221-222

Greenwood AW and Blyth JS (1938) Experimental modification of the accessory sexual apparatus in the hen Journal of Experimental Physiology 28 61-69

Guillette LJ, Gross TS, Masson GR, Matter JM, Percival HF and Woodward AR (1994) Developmental abnormalities of the gonad and abnormal sex hormone concentrations in juvenile alligators from contaminated and control lakes in Florida Environmental Health Perspectives 102 680-688

Guillette LJ, Crain DA, Rooney AA and Pickford DB (1995) Organization versus activation: the role of endocrine-disrupting contaminants (EDCs) during embryonic development in wildlife Environmental Health Perspectives 103 (Supplement 7) 157-164

Kohler P, Grimley PM and O'Malley BW (1969) Estrogen-induced cytodifferentiation of the ovalbumin-secreting glands of the chick oviduct Journal of Cell Biology 40 8-27

Larsson DGJ, Adolfsson-Erici M, Parkkonen J, Petterson M, Berg AH, Olsson P-E and Förlin L (1999) Ethinylestradiol - an undesired fish contraceptive? Aquatic Toxicology 45 91-97

Oka T and Schimke RT (1969) Interaction of estrogen and progesterone in chick oviduct development Journal of Cell Biology 41 816-831

Pageaux JF, Laugier C, Pal D and Pacheco H (1984) Development of the oviduct in quail during sexual maturation in relation to plasma concentrations of oestradiol and progesterone Journal of Endocrinology $100167-173$

Palmiter R and Wrenn J (1971) Interaction of estrogen and progesterone in chick oviduct development Journal of Cell Biology 50 598-615

Rissman EF, Ascenzi M, Johnson P and Adkins-Regan A (1984) Effects of embryonic treatment with oestradiol benzoate on reproductive morphology, ovulation and oviposition and plasma LH concentrations in female quail Journal of Reproduction and Fertility 71 411-417

Sandoz D, Ulrich E and Brard E (1971) Étude des ultrastructures du magnum des oiseaux Journal de Microscopie 11 371-400

Sandoz D, Boisvieux-Ulrich E, Laugier C and Brard E (1975) Interactions du benzoated oestradiol et de la progesterone sur le developpement de l'oviducte de Caille (Coturnix coturnix japonica) General and Comparative Endocrinology 26 451-467

Teng CS and Teng CT (1979) Prenatal effect of the estrogenic hormone on embryonic genital organ differentiation. In Ontogeny of Receptors and Reproductive Hormone Action pp 421-440 Eds TH Hamilton, WA Sadler and JH Clark. Raven Press, New York

Tyler CR, Jobling S and Sumpter JP (1998) Endocrine disruption in wildlife: a critical review of the evidence Critical Reviews in Toxicology 28 319-360

Vos JG, Dybing E, Greim HA, Ladevoged O, Lambré C, Tarazona JV, Brandt I and Vethaak AD (2000) Health effects of endocrine disrupting chemicals on wildlife, with special reference to the European situation Critical Reviews in Toxicology 30 71-133

Revised manuscript received 11 July 2000.

Revised manuscript accepted 17 July 2000. 